\title{
Impact of Angiotensin-Converting Enzyme Inhibitors/Angiotensin Receptor Blockers on Renal Function in Chronic Kidney Disease Patients Undergoing Coronary Angiography
}

Arunee T. Motes ${ }^{1}$, Praveen Ratanasrimetha ${ }^{2}$, Sariya Wongsaengsak ${ }^{1}$, Yuttiwat Vorakunthada ${ }^{3}$, Thammasak Mingbunjerdsuk ${ }^{4}$, Camillo Pena ${ }^{5}$, Kenneth Nugent ${ }^{6}$

\begin{abstract}
1. Internal Medicine, Texas Tech University Health Sciences Center, Lubbock, USA 2. Internal Medicine/Nephrology, University of Pittsburgh Medical Center, Pittsburgh, USA 3. Internal Medicine/Pulmonary Medicine, Critical Care and Sleep Medicine, University of Arizona College of Medicine - Phoenix, Phoenix, USA 4. Internal

Medicine/Gastroenterology, University of Kentucky College of Medicine, Lexington, USA 5. Internal

Medicine/Nephrology, Texas Tech University Health Sciences Center, Lubbock, USA 6. Internal Medicine/Pulmonary and Critical Care Medicine, Texas Tech University Health Sciences Center, Lubbock, USA
\end{abstract}

Corresponding author: Arunee T. Motes, arunee.motes@ttuhsc.edu

\begin{abstract}
Background: Cardiac catheterizations and coronary angiography are minimally invasive methods for studying the heart and the coronary arteries, using iodinated radiocontrast agents which can cause acute kidney injury (AKI). Angiotensin-converting enzyme (ACE) inhibitors and angiotensin receptor blockers (ARB) are widely used due to their well-established benefit in coronary artery disease and renal protection in diabetes mellitus. Renin-angiotensin-aldosterone system inhibitors can induce AKI in some patients.
\end{abstract}

Method: This study analyzed the effect of radiocontrast media used for coronary angiography on renal function in patients with chronic kidney disease (CKD) stages 2-5 who also took ACE inhibitors/ARB medications. Information was collected from the electronic medical records of 116 cases to determine changes in serum creatinine following angiography.

Result: The average age of patients was $65.2 \pm 12.3$ years. There were 89 men (76.7\%) and 27 women (23.3\%). Six patients had documented ACE inhibitor discontinuation, and one patient had documented ARB discontinuation prior to their procedures. Based on the criteria of an increase in serum creatinine ( $\mathrm{SCr}$ ) by $\geqslant 0.3 \mathrm{mg} / \mathrm{dl}$ within 48 hours, 19 cases (16.4\%) had AKI. Based on the criteria of increasing in SCr to $\geqslant 1.5$ times baseline, AKI developed in 2 cases $(1.7 \%)$ on day 1,4 cases $(3.5 \%)$ on day 2 , and 7 cases $(6.0 \%)$ on day 3 after coronary angiography.

Review began 01/08/2021 Review ended 01/14/2021 Published 01/20/2021

\section{() Copyright 2021}

Motes et al. This is an open access article distributed under the terms of the Creative Commons Attribution License CC-BY 4.0., which permits unrestricted use, distribution, and reproduction in any medium, provided the original author and source are credited.
Conclusion: This study suggests that the continuation of ACE inhibitors/ARB does not appear to have any important effect or association with changes in renal function, within one-month post angiography in patients with CKD stages 2-5.

Categories: Cardiology, Internal Medicine, Nephrology

Keywords: angiotensin-converting enzyme inhibitors, angiotensin receptor blockers, contrast-induced acute kidney injury, coronary angiography

\section{Introduction}

More than a million cardiac catheterizations and coronary angiographies are performed every year in the United States. These are minimally invasive methods for studying the heart and the coronary arteries using iodinated radiocontrast agents that can cause acute kidney injury (AKI) [1]. Contrast-induced AKI is defined as any case of AKI occurring 48-72 hours after the intravascular injection of contrast media that cannot be attributed to other causes. It occurs more frequently in older patients, in patients with diabetes, and in patients with underlying renal insufficiency [2]. Contrast-induced nephropathy is a major cause of newonset renal failure in hospitalized patients, and increased hospital length of stay and in-hospital mortality are directly related to the severity of contrast-induced nephropathy [3,4]. The reported rate of AKI after coronary catheterization ranges between $2 \%$ and $25 \%[5,6]$. Patients with contrast-induced nephropathy who require dialysis have an in-hospital mortality rate close to $40 \%$ and two-year survival of less than $20 \%[7,8]$.

The reported risk of contrast-induced AKI is much higher with procedures involving the arterial administration of contrast, e.g., coronary angiography, than the venous administration of contrast. This difference in risk may be due to differences in patient populations since the patients who require arterial contrast are more likely to have comorbidities that increase the likelihood of developing AKI or due to differences in the nephrotoxicity associated with the intra-arterial administration of contrast in comparison to the intravenous administration of contrast [1]. 
Angiotensin-converting enzyme (ACE) inhibitors and angiotensin receptor blockers (ARB) are widely used for their well-established benefit in reducing morbidity and mortality in patients with coronary artery disease and for renal protection in patients with diabetes mellitus. ACE inhibition can induce AKI in patients in whom glomerular filtration is critically dependent on angiotensin II-mediated efferent vascular tone, such as in patients with renal arterial disease or in patients with heart failure and severe volume depletion [9]. Despite the fact that ACE inhibition can contribute to AKI in certain conditions, it remains controversial whether ACE inhibitor or ARB medications should be discontinued prior to coronary angiography to minimize post-procedure AKI. According to the Kidney Disease-Improving Global Outcomes guidelines for $\mathrm{AKI}$, there is insufficient evidence to recommend discontinuation of these drugs in patients undergoing injection of contrast drugs [10].

In this study, we wanted to determine if radiocontrast exposure during coronary angiography causes deterioration in renal function in patients with CKD stages 2-5 who are not on dialysis and who take ACE inhibitor/ARB medications. These patients are often older and have comorbidity relevant to renal disease. We investigated the incidence of AKI after coronary angiography in CKD patients taking ACEI/ARB medication during the 30 days prior to the procedure.

\section{Materials And Methods}

We included patients with CKD stages 2-5 (estimated glomerular filtration rate $[\mathrm{eGFR}]<90 \mathrm{ml} / \mathrm{min}$ ) who took ACE inhibitor/ARB medications $\geqslant 1$ month before coronary angiography and were evaluated in our hospital between January 1, 2015, and December 31, 2016. We excluded CKD patients who were less than 18 years old, pregnant, on dialysis, or kidney transplant recipients. The eGFR in our hospital laboratory is based on the Modification of Diet in Renal Disease (MDRD) Study equation. This study was approved by the Institutional Review Board at Texas Tech University Health Sciences Center (L18-079) in Lubbock, Texas.

A total of 116 cases were included in the study. From electronic medical records, we collected information on gender, age, cardiac disorders, comorbidities, diabetes mellitus, hypertension, the presence of proteinuria, amount of proteinuria in spot urine samples, CKD stages 2-5, ACE inhibitor medication, ACE inhibitor medication discontinuation, ARB medication, ARB medication discontinuation, non-steroidal antiinflammatory drugs use, date of coronary angiography, serum creatinine (SCr)/eGFR before coronary angiography, SCr/eGFR on day 1 after coronary angiography, SCr/eGFR on day 2 after coronary angiography, SCr/eGFR on day 3 after coronary angiography, SCr/eGFR one month after coronary angiography, length of hospital stay, rehospitalization, repeat coronary angiography, and cardiovascular complications. Patients undergoing cardiac catheterization and angiography in our cardiac catheterization lab receive individualized periprocedural fluid management; there is no standard fluid protocol. A low osmolar contrast agent, such as Visipaque (VISIPAQUE ${ }^{\mathrm{TM}}$ (iodixanol) injection | GE Healthcare, Chicago, IL), was used in the catheterization procedures. This lab did not consistently record contrast volumes. There was also limited information in the medical records about the discontinuation of the ACE inhibitor/ARB medications. The catheterization lab does not have a consistent policy regarding the use of these medications prior to catheterization. Consequently, it was difficult to determine which patients had the medications discontinued and who did not and the timeframe for any discontinuation; therefore, the collected data were interpreted as if the patients continued to take ACE inhibitor/ARB medications prior to the procedure. This lab did not consistently record contrast volumes.

\section{Results}

The average age of patients was $65.2 \pm 12.3$ years (Table 1$)$. There were 89 men $(76.7 \%)$ and 27 women (23.3\%). Among the 116 cases, six cases had documented ACE inhibitor discontinuation, and one case had documented ARB discontinuation prior to the procedure. Twenty-nine cases had CKD stages 4 and 5 prior to coronary angiography; 44 cases had proteinuria with spot urine protein levels varying from $30 \mathrm{mg} / \mathrm{dl}$ to more than $600 \mathrm{mg} / \mathrm{dL}$. There were 76 patients (65.5\%) who had diabetes mellitus and 97 patients (83.6\%) who had hypertension. Thirteen cases underwent repeat coronary angiography, and 12 cases developed cardiovascular complications, including cardiogenic shock, arrhythmia, cardiac arrest, and heart failure. Fifteen patients required rehospitalization for any cause after the coronary angiography. 


\section{Cureus}

\begin{tabular}{|c|c|c|}
\hline Parameter & Number & Percentage (\%) \\
\hline \multicolumn{3}{|l|}{ Gender } \\
\hline Male & 89 & 76.72 \\
\hline Female & 27 & 23.28 \\
\hline \multicolumn{3}{|l|}{ Age (years) } \\
\hline $18-20$ & 0 & 0.00 \\
\hline $21-30$ & 0 & 0.00 \\
\hline $31-40$ & 3 & 2.59 \\
\hline $41-50$ & 14 & 12.07 \\
\hline $51-60$ & 24 & 20.69 \\
\hline $61-70$ & 32 & 27.59 \\
\hline $71-80$ & 34 & 29.31 \\
\hline $81-90$ & 7 & 6.03 \\
\hline$>90$ & 2 & 1.72 \\
\hline \multicolumn{3}{|l|}{ Cardiac disorders } \\
\hline Coronary artery disease & 71 & 61.21 \\
\hline Heart failure & 26 & 22.41 \\
\hline Atrial fibrillation & 8 & 6.90 \\
\hline \multicolumn{3}{|l|}{ Comorbidity } \\
\hline Diabetes mellitus & 76 & 65.52 \\
\hline Hypertension & 97 & 83.62 \\
\hline CKD stage 4-5 & 29 & 25.00 \\
\hline Proteinuria & 44 & 37.93 \\
\hline NSAID use & 4 & 3.45 \\
\hline \multicolumn{3}{|l|}{ ACEI } \\
\hline Lisinopril & 91 & 78.45 \\
\hline Enalapril & 5 & 4.31 \\
\hline Captopril & 6 & 5.17 \\
\hline Ramipril & 3 & 2.59 \\
\hline \multicolumn{3}{|l|}{ ARB } \\
\hline Losartan & 3 & 2.59 \\
\hline Valsartan & 4 & 3.45 \\
\hline Candesartan & 3 & 2.59 \\
\hline Olmesartan & 1 & 0.86 \\
\hline
\end{tabular}

\section{TABLE 1: Demographic data}

ACEI: angiotensin-converting enzyme inhibitor, ARB: angiotensin receptor blocker, CKD: chronic kidney disease, NSAID: nonsteroidal antiinflammatory drug. 
Based on the criterion of increasing SCr by $\geqslant 0.3 \mathrm{mg} / \mathrm{dl}$ within 48 hours, 19 cases (16.4\%) had AKI. Based on the criterion of increasing $\mathrm{SCr}$ to $\geqslant 1.5$ times baseline, which was available within the prior seven days, AKI was diagnosed in two cases (1.7\%) on day 1 , in four cases (3.5\%) on day 2 , and in seven cases $(6.0 \%)$ on day 3 after coronary angiography. Urine volumes were not measured after coronary angiography.

Table 2 reports the average SCr and eGFR. The average SCrs in $\mathrm{mg} / \mathrm{dL}$ were 2.30, 1.97, 2.00, 1.93, and 2.21 at baseline, day 1 , day 2 , day 3 , and one month after coronary angiography, respectively. Average eGFRs in $\mathrm{ml} /$ minute were $44.17,43.70,41.83,43.58$, and 42.88 at baseline, day 1 , day 2 , day 3 , and 1 month after coronary angiography, respectively. The mean eGFR in patients classified by CKD stage are reported in Table 3. Eighty-three cases out of 116 cases had documented SCr at one month. Post-procedure, thirty-five cases (42.2\% of 83 ) had increased $\mathrm{SCr}$ at one month compared to their baseline, 35 cases (42.2\%) had decreased SCr compared to their baseline, and 13 cases (15.6\%) had unchanged SCr compared to their baseline.

\begin{tabular}{|c|c|c|c|c|c|}
\hline & Baseline & Day 1 & Day 2 & Day 3 & 1 month \\
\hline Average $\mathrm{SCr}(\mathrm{mg} / \mathrm{dll})$ & $2.03 \pm 1.54$ & $1.97 \pm 1.43$ & $2.0 \pm 1.20$ & $1.93 \pm 1.17$ & $2.21 \pm 1.69$ \\
\hline Average eGFR (ml/min) & $44.17 \pm 18.92$ & $43.7 \pm 18.03$ & $41.83 \pm 18.80$ & $43.58 \pm 19.16$ & $42.88 \pm 21.58$ \\
\hline
\end{tabular}

\section{TABLE 2: Average SCr and eGFR before and after coronary angiography}

SCr: serum creatinine, eGFR: estimated glomerular filtration rate.

\begin{tabular}{|c|c|c|c|c|c|c|}
\hline \multirow{2}{*}{ CKD stage } & \multirow{2}{*}{ Number } & \multicolumn{5}{|c|}{ Average eGFR \pm SD } \\
\hline & & Before $\mathrm{PCl}$ & Day 1 & Day 2 & Day 3 & 1 month \\
\hline 2 & 22 & $68.73 \pm 7.57$ & $62.48 \pm 11.78$ & $60.7 \pm 15.17$ & $62.4 \pm 13.85$ & $62.81 \pm 16.55$ \\
\hline $3 a$ & 40 & $52.22 \pm 4.82$ & $51.99 \pm 10.47$ & $47.49 \pm 16.66$ & $45.97 \pm 17.68$ & $54.04 \pm 13.79$ \\
\hline $3 b$ & 25 & $39.5 \pm 4.75$ & $42.62 \pm 9.54$ & $40.39 \pm 10.80$ & $42.15 \pm 12.85$ & $38.99 \pm 9.91$ \\
\hline 4 & 15 & $24.88 \pm 3.30$ & $25.23 \pm 6.63$ & $25.28 \pm 8.49$ & $27.53 \pm 10.84$ & $28.24 \pm 21.35$ \\
\hline 5 & 14 & $11.12 \pm 3.24$ & $12.56 \pm 4.78$ & $16.3 \pm 11.14$ & $16.35 \pm 8.95$ & $12.82 \pm 8.25$ \\
\hline
\end{tabular}

\section{TABLE 3: Estimated GFR before and after angiography in each stage of CKD}

CKD: chronic kidney disease, eGFR: estimated glomerular filtration rate, PCI: percutaneous coronary intervention.

In the ACE inhibitor/ARB discontinuation group $(\mathrm{n}=7)$, the mean eGFR $\pm \mathrm{SD}$ in $\mathrm{ml} /$ minute were $36.00 \pm 12.06$, $37.92 \pm 10.94,35.11 \pm 8.03,35.02 \pm 7.56$, and $35.21 \pm 5.70$ before the procedure, at day 1 , day 2 , day 3 , and one month after coronary angiography, respectively.

\section{Discussion}

This study revealed that the continuation of the ACE inhibitor/ARB medications is not associated with significant renal injury in older patients with CKD stages $2-5$ baseline renal disease undergoing coronary angiography. These results suggest that patients can continue ACE inhibitor/ARB medications during and after cardiac catheterization procedures provided that no intercurrent illness dictates an alternative plan.

Angiotensin II is a potent vasoconstrictor of the systemic and renal vascular beds. Consequently, ACE inhibitors cause systemic and renal vasodilation, resulting in a fall in blood pressure and an increase in renal blood flow. As renal vasodilation mainly occurs in the efferent arteriole, glomerular filtration pressure is reduced by ACE inhibition. Simultaneously, angiotensin II induces mesangial cell contraction, resulting in an increase in the surface area available for filtration. As a consequence, the decreased filtration pressure does not cause a reduction in glomerular filtration rate, as it is counterbalanced by the simultaneous increases in renal blood flow and glomerular filtration area. However, in conditions in which glomerular filtration is critically dependent on angiotensin II-mediated efferent vascular tones, such as with a poststenotic kidney or with heart failure and severe volume depletion, ACE inhibition can induce AKI, which is usually reversible after withdrawal of the drug [9]. 
A recent systematic review and meta-analysis study that included three randomized controlled trials (RCTs) and three prospective cohort studies (1663 total participants) revealed that there is low-quality evidence that demonstrates that withdrawal of ACE inhibitor/ARB medications prior to coronary angiography and cardiac surgery reduces the incidence of AKI and there was no evidence that drug discontinuation reduces the incidence of AKI during intercurrent illness in primary or secondary care [11].

Wolak et al. randomized patients into three groups, i.e., group A (ACE inhibitor/ARB stopped 24 hours prior to the procedure and restarted immediately after the procedure), group B (ACE inhibitor/ARB stopped 24 hours prior to the procedure and restarted 24 hours after the procedure), and group C (ACE inhibitor/ARB continued throughout the study period) (total $\mathrm{N}=94$ ) and concluded that ACE inhibitors and ARB medications can be safely used before and after coronary angiography in patients with an eGFR $\geqslant 60 \mathrm{ml} / \mathrm{min}$. However, post-hoc analysis in this study suggested that it might be advisable to discontinue ACEI/ARB at least 24 hours before coronary angiography in patients with eGFR $<60 \mathrm{ml} / \mathrm{min}$ [12]. An RCT with 220 patients reported that withholding ACE inhibitor and ARB medications 24 hours before coronary angiography does not alter the incidence of contrast-induced nephropathy in stable patients with CKD stages 3-4 (eGFR 15-60 ml/min) [13]. Bainey et al. demonstrated that in patients $(\mathrm{N}=208)$ with moderate renal insufficiency undergoing cardiac catheterization withholding ACE inhibitor/ARB medications resulted in a non-significant reduction in contrast-induced AKI and a significant reduction in the post-procedural rise of creatinine. This low-cost intervention could be considered when referring a patient for cardiac catheterization [14]. These studies are summarized in Table 4.

\begin{tabular}{|c|c|c|c|c|}
\hline & Our study & Wolak et al. [12] & Rosenstock et al. [13] & Bainey et al. [14] \\
\hline Study design & Retrospective & RCT & RCT & RCT \\
\hline Iıme period & January 2015 - June 2017 & $\begin{array}{l}\text { April } 2010 \text { - September } \\
2010\end{array}$ & No detalls & July 2006 - March 2012 \\
\hline Sample size & 116 & 94 & 220 & 208 \\
\hline Mean age & $65 \pm 12$ & $65 \pm 12$ & $72 \pm 10$ & $73 \pm 9$ \\
\hline Female (\%) & 23 & 33 & 52 & 26 \\
\hline Risk group & CKD stages 2-5 & None & CKD stages 3-4 & CKD stage 3 \\
\hline Baseline SCr & $2.03 \pm 1.5$ & $1.01 \pm 0.4$ & $1.5 \pm 0.4$ & $1.6 \pm 0.4$ \\
\hline Comorbidities & $\begin{array}{l}\text { Hypertension }(83.6 \%) \text {, } \\
\text { diabetes }(62.5 \%) \text {, heart } \\
\text { failure }(22.4 \%) \text {, A-fib }(6.9 \%)\end{array}$ & $\begin{array}{l}\text { Unstable angina }(62 \%) \text {, } \\
\text { diabetes }(50 \%)\end{array}$ & $\begin{array}{l}\text { Hypertension (97\%), diabetes } \\
(54 \%)\end{array}$ & $\begin{array}{l}\text { Diabetes }(54 \%) \text {, hypertension }(47 \%) \text {, } \\
\text { heart failure }(14 \%)\end{array}$ \\
\hline AKI definition & $\begin{array}{l}\text { Increase in } \mathrm{SCr} \text { by } \geq 0.3 \\
\mathrm{mg} / \mathrm{dl} \text { within } 48 \text { hours or } \\
\text { increase in } \mathrm{SCr} \text { to } \geq 1.5 \\
\text { times baseline }\end{array}$ & $\begin{array}{l}\text { Increase in SCr by } \\
\geq 25 \% \text { from baseline }\end{array}$ & $\begin{array}{l}\text { Increase in SCr by }>25 \% \text { or } \\
\geq 0.5 \mathrm{mg} \text { from baseline }\end{array}$ & $\begin{array}{l}\text { Increase in SCr by } \geq 25 \% \text { or } \geq 0.5 \mathrm{mg} \\
\text { from baseline }\end{array}$ \\
\hline Study drug & ACEI/ARB & ACEI/ARB & ACEI/ARB & ACEI/ARB \\
\hline IIme of hold & Insufficient data & $\begin{array}{l}24 \text { hours prior to the } \\
\text { procedure }\end{array}$ & Day of procedure & 24 hours prior to the procedure \\
\hline Procedure & Coronary angiogram & Coronary angiogram & Coronary angiogram & Coronary angiogram \\
\hline $\begin{array}{l}\text { Study } \\
\text { outcome }\end{array}$ & $\begin{array}{l}\text { There is no definite } \\
\text { evidence to indicate that } \\
\text { angiography causes AKI in } \\
\text { CKD stages } 2-5 \text { patients } \\
\text { who take ACEI/ARB. }\end{array}$ & $\begin{array}{l}\text { ACEl and ARB can } \\
\text { safely be used before } \\
\text { and after angiography in } \\
\text { patients with eGFR } \geq 60 \\
\mathrm{ml} / \text { minutes }\end{array}$ & $\begin{array}{l}\text { Withholding ACEls and ARBs } \\
24 \mathrm{~h} \text { before angiography does } \\
\text { not alter the incidence of CIN } \\
\text { in stable patients with CKD } \\
\text { stages 3-4. }\end{array}$ & $\begin{array}{l}\text { Withholding ACEI/ARB resulted in a } \\
\text { non-significant reduction in contrast- } \\
\text { induced AKI and a significant } \\
\text { reduction in the post-procedural rise } \\
\text { of creatinine. }\end{array}$ \\
\hline $\begin{array}{l}\text { SCr: serum crea } \\
\text { receptor blocke } \\
\text { trial. }\end{array}$ & tine, AKI: acute kidney injury, & $\begin{array}{l}\text { D: chronic kidney disea } \\
\text { tration rate, A-fib: atrial }\end{array}$ & $\begin{array}{l}\text { ACEI: angiotensin-converting } \\
\text { illation, CIN: contrast-induced }\end{array}$ & $\begin{array}{l}\text { izyme inhibitor, ARB: angiotensin } \\
\text { phropathy, RCT: randomized controlled }\end{array}$ \\
\hline
\end{tabular}

Mehran et al. have reviewed contrast-induced nephropathy and discussed the possibility that avoiding needed contrast studies might do more harm than undertaking the studies in some patients [15]. Therefore, 
patient evaluation requires careful consideration of the risks and benefits associated with the procedure. In addition, the best method for reducing renal injury involves the use of intravenous saline before and after the procedure, but the best protocol for this is uncertain.

Our study has several limitations. First, in a retrospective study, it is difficult to determine causal relationships in complicated patients. Second, there was limited information in the medical records about ACE inhibitor/ARB medication discontinuation. The catheterization lab does not have a consistent policy regarding the use of these medications prior to catheterization. Consequently, it was difficult to determine which patients had the medications discontinued and which patients did not and the timeframe for any discontinuation. Therefore, the collected data were interpreted as if the patients continued to take ACE inhibitor/ARB medications prior to the procedure. We did not find any significant difference between baseline average SCr and average SCr at 48 hours after the procedure, and the average SCr at 72 hours was, in fact, lower than baseline average SCr. Third, the records did not provide consistent information on the volume of contrast use during procedures. Future studies should include the timeframe for the discontinuation of the ACE inhibitor/ARB medication, and information about the blood pressures prior to and after cardiac catheterization.

\section{Conclusions}

This study suggests that the continuation of ACE inhibitor/ARB medications does not appear to have any important effect or association with changes in renal function within one month post angiography in patients with CKD stages 2-5. This information should help hospitalists and cardiologists schedule coronary catheterization studies with the most efficient use of hospital time. Of course, all patients with chronic renal disease need careful clinical assessment before any procedure involving catheterization and contrast injection.

\section{Additional Information \\ Disclosures}

Human subjects: Consent was obtained or waived by all participants in this study. The Institutional Review Board at Texas Tech University Health Sciences Center issued approval IRB\#: L18-079. This study was approved by the Institutional Review Board at Texas Tech University Health Sciences Center (L18-079) in Lubbock, Texas. Animal subjects: All authors have confirmed that this study did not involve animal subjects or tissue. Conflicts of interest: In compliance with the ICMJE uniform disclosure form, all authors declare the following: Payment/services info: All authors have declared that no financial support was received from any organization for the submitted work. Financial relationships: All authors have declared that they have no financial relationships at present or within the previous three years with any organizations that might have an interest in the submitted work. Other relationships: All authors have declared that there are no other relationships or activities that could appear to have influenced the submitted work.

\section{References}

1. Prevention of contrast-induced acute kidney injury associated with angiography . (2020). Accessed: March 23, 2020: https://www.uptodate.com/contents/prevention-of-contrast-induced-acute-kidney-injuryassociated-with-angiography?topi....

2. Navis G, Faber HJ, de Zeeuw D, de Jong PE: ACE inhibitors and the kidney. A risk-benefit assessment . Drug Saf. 1996, 15:200-211. 10.2165/00002018-199615030-00005

3. Hou SH, Bushinsky DA, Wish JB, Cohen JJ, Harrington JT: Hospital-acquired renal insufficiency: a prospective study. Am J Med. 1983, 74:243-8. 10.1016/0002-9343(83)90618-6

4. Shema L, Ore L, Geron R, Kristal B: Contrast-induced nephropathy among Israeli hospitalized patients: incidence, risk factors, length of stay and mortality. Isr Med Assoc J. 2009, 11:460-4.

5. Merhan R, Aymong ED, Nikolsky E, et al.: A simple risk score for prediction of contrast-induced nephropathy after percutaneous coronary intervention: development and initial validation. J Am Coll Cardiol. 2004, 44:1393-9. 10.1016/j.jacc.2004.06.068

6. Solomon R, Dauerman HL: Contrast-induced acute kidney injury. Circulation. 2010, 122:2451-5. 10.1161/CIRCULATIONAHA.110.953851

7. McCullough PA, Wolyn R, Rocher LL, Levin RN, O’Neill WW: Acute renal failure after coronary intervention: incidence, risk factors, and relationship to mortality. Am J Med. 1997, 103:368-75. 10.1016/S0002-9343(97)00150-2

8. McCullough PA, Adam A, Becker CR, et al.: Epidemiology and prognostic implications of contrast-induced nephropathy. Am J Cardiol. 2006, 98:5-13. 10.1016/j.amjcard.2006.01.019

9. Andreucci M, Faga T, Serra R, De Sarro G, Michael A: Update on the renal toxicity of iodinated contrast drugs used in clinical medicine. Drug Healthc Patient Saf. 2017, 9:25-37. 10.2147/DHPS.S122207

10. Khwaja A: KDIGO clinical practice guideline for acute kidney injury . Nephron Clin Pract. 2012, 120:c179-84. 10.1159/000339789

11. Whiting P, Morden A, Tomlinson LA, et al.: What are the risks and benefits of temporarily discontinuing medications to prevent acute kidney injury? A systematic review and meta-analysis. BMJ Open. 2017, 7:e012674. 10.1136/bmjopen-2016-012674

12. Wolak T, Aliev E, Rogachev B, Baumfeld Y, Cafri C, Abu-Shakra M, Novack V: Renal safety and angiotensin II blockade medications in patients undergoing non-emergent coronary angiography: a randomized 


\section{Cureus}

controlled study. Isr Med Assoc J. 2013, 15:682-7.

13. Rosenstock JL, Bruno R, Kim JK, et al.: The effect of withdrawal of ACE inhibitors or angiotensin receptor blockers prior to coronary angiography on the incidence of contrast-induced nephropathy. Int Urol Nephrol. 2008, 40:749-55. 10.1007/s11255-008-9368-1

14. Bainey KR, Rahim S, Etherington K, et al.: Effects of withdrawing vs continuing renin-angiotensin blockers on incidence of acute kidney injury in patients with renal insufficiency undergoing cardiac catheterization: Results from the Angiotensin Converting Enzyme Inhibitor/Angiotensin Receptor Blocker and Contrast Induced Nephropathy in Patients Receiving Cardiac Catheterization (CAPTAIN) trial. Am Heart J. 2015, 170:110-6. 10.1016/j.ahj.2015.04.019

15. Mohandas R, Dass B, Ejaz AA: Contrast associated acute kidney injury. New Engl J Med. 2019, 381:1295. 10.1056/NEJMc1908879 